\title{
The impact of California anti-smoking legislation on cigarette sales, consumption, and prices
}

\author{
Teh-wei Hu, Theodore E Keeler, Hai-yen Sung, Paul G Barnett
}

\section{University of California at Berkeley, Berkeley, California, USA: School of Public Health T Hu Department of Economics TE Keeler Institute of Business and Economic Research $\mathrm{H}$ Sung \\ Center for Health Care Evaluation, Veterans Affairs Medical Center, Berkeley, California, USA \\ PG Barnett}

Correspondence to: Teh-wei $\mathrm{Hu}$, Room 412 Warren Hall School of Public Health University of California, Berkeley, CA 94720-7360, USA

\begin{abstract}
Objective - To integrate and analyse the economic effects of California's Proposition 99, increasing state excise tax on cigarettes by 25 cents per pack, on the retail price of cigarettes and total state cigarette consumption, among other factors; and to summarise the reduction of smoking resulting from a media advertising campaign financed by Proposition 99.
\end{abstract}

Design - Econometric models and aggregate data on cigarette prices and consumption were used for the analysis.

Subjects-People of California and the USA; for analysis of pricing behaviour, the major cigarette firms and the retailers of California and the USA.

Results - The higher prices from Proposition 99 reduced cigarette consumption by $8-10 \%$ in the short run and $10-13 \%$ in the long run. The media campaign had a significant effect in further reducing cigarette consumption, though the effects of that campaign are substantially weaker than those of the tax increase. Conclusion - Proposition 99 has achieved many of its goals.

(Tobacco Control 1995; 4 (suppl 1): S34-S38) Keywords: anti-smoking legislation; cigarette sales; cigarette consumption

wide anti-smoking multimedia campaign. Some $\$ 15$ million a year are spent on antismoking advertisements targeted at minorities, pregnant women, and children. Advertisements appear on television, radio, newspapers, and billboards.

Proposition 99 was the first state legislation in the USA which sought to deter cigarette consumption with an increase in the state excise tax and an anti-smoking campaign. It represents a unique natural experiment. This paper reports the results of several studies by this research team that sought to answer the following questions about Proposition 99. (1) What were the effects on the retail prices of cigarettes? (2) What were the effects of the tax on the quantity of cigarettes demanded or on cigarette sales? (3) How were tax revenues spent? (4) Given that an anti-smoking media campaign is a part of Proposition 99, what parts of the total effects were due to the tax increase, and what parts were due to the antismoking campaign?

The goal of this paper was to learn from California's experience and assist those who are considering similar legislation for the federal government, for other states and for other countries. In the next section we shall summarize the results of our studies on the impacts of Proposition 99. These studies are classifiable into two broad categories: structural analysis of supply and demand models for cigarettes, and time series analysis. The final section contains conclusions and policy implications, together with a discussion on a further policy-relevant question: what has the state done with revenues from Proposition 99? 99, the California Tobacco and Health Promotion Act. Proposition 99 increased the state excise tax on cigarettes from 10 cents per pack to 35 cents. It also specified how the new tax revenue was to be used, including health education programmes for the prevention and reduction of tobacco use, indigent health care, research, parks, recreation, environmental programmes, and other activities.

Some $\$ 125$ million a year have been allocated for health education. Funds are administered by the state Department of Education and Health Services. The Department of Education makes grants in support of school-based anti-smoking programmes. The Department of Health Services funds anti-smoking efforts by local health departments, and a programme of competitive grants to community agencies. In addition, it supports the most visible component of the anti-smoking effort, a state-

\section{Methods and findings}

The effects of a tax increase can be divided, in economic terms, between effects on supply (that is, the extent to which the retail price of cigarettes goes up by more than, less than, or the same as the tax increase), and effects of demand (the extent to which cigarette consumption declines in response to the higher price). Time-series analysis combines analysis of both effects into a single equation, whereas structural analysis measures supply and demand behaviour separately and combines the two to analyse the effects of a tax increase on consumption.

In this paper, we shall first summarise the models and results from our structural analysis of the separate effects on cigarette price and 
cigarette consumption, and the integrated supply and demand effects. We shall then analyse the effects of the taxation on cigarette consumption based on our time-series analysis.

STRUCTURAL ANALYSIS OF PROPOSITION 99

As stated above, structural analysis requires separate consideration of supply and demand for cigarettes, and then the effects of supply and demand can be combined.

\section{Supply effects - the impact of taxes on the retail price of cigarettes}

Most studies on the impact of taxation on cigarette consumption have used a single equation demand model to test the effect of price on the demand for cigarettes. Such a model assumes that the cigarette industry is perfectly competitive and the supply is perfectly flat (that is, constant cost), so that the excise tax change will be fully reflected in cigarette prices. ${ }^{1}$ Evidence suggests, however, that the cigarette industry is not perfectly competitive and that when cigarette taxes rise, prices have often risen more than the amount of the tax increase. ${ }^{2}$ Therefore, we also need to evaluate how the change in excise tax affects the retail price of cigarettes in order to correctly measure the impact of taxation on cigarette consumption.

The effect of a cigarette tax on cigarette price depends on underlying industry pricing behaviour. Economic theory and our empirical analysis indicate that the ability of the industry to pass on taxes in prices depends on industry market power (that is, competition, oligopoly, or monopoly) and the consumer's responsiveness to increases in price (that is, demand elasticity). For instance, a typical competitive industry with a flat long run supply curve will pass on the full amount of a tax (no more and no less). A monopoly could pass on more than the amount of a tax or would absorb some amount of a tax, depending on the shape of the demand curve. ${ }^{3,4}$

Although most observers of the cigarette industry agree that manufacturers enjoy some market power (and hence are an oligopoly, rather than being either perfectly competitive or monopolistic), there is less agreement as to just how the industry coordinates its prices. If an oligopoly coordinates its prices and outputs closely, its prices can approach those of a monopolist. If it coordinates little, its outcome in prices and quantities will more closely approximate those of a competitive market.

Behaviour regarding passing on a tax is more complicated still if the tax is for one of many states. The extent to which the tax can be passed on is then a function of the size of the state, the degree of competition in the wholesale and retail markets, and the extent to which wholesalers and consumers are free to arbitrage prices across state lines (thus, a tobacco company selling to a large retailer, such as Walmart, would have difficulty charging different wholesale prices for cigarettes sold in Minnesota and California, because Walmart could buy the cigarettes wholesale at a single price and sell the cigarettes in each state at prices reflecting competition and market conditions in those sates).

There is yet a further complication in analysis of the effects taxes on retail prices of cigarettes. The oligopoly of cigarette manufacturers is unlikely to maintain the same degree of coordination over time (that is, depending on how well it is coordinating at a given point in time, it may charge $3 / 4$ the monopoly price or $7 / 8$ the monopoly price, etc). If the degree of coordination changes at the same approximate time as a tax is imposed, it will be difficult to separate the effects of the tax from the effects of the changed coordination. Indeed, Harris ${ }^{5}$ has argued that, as federal taxes were raised in 1983, the cigarette manufacturers' oligopoly used the tax change as a signal to increase coordination.

The point of the above discussion is that any analysis of the supply effects of a cigarette tax change must deal with all the above conceptual and empirical issues. In our opinion, no empirical study has disentangled all these effects with complete success. Though the results summarised below are our best efforts so far, further research is clearly needed on the supply effects of taxes, at both federal and state levels.

To account for the variation of taxes, Sung et $a l^{6}$ take into account both supply and demand models for cigarettes, estimated with data pooled for 11 western states on aggregate cigarette sales published by The Tobacco Institute ${ }^{7}$ between 1967 and 1990. By pooling data of states near California, the possibility of bootlegging into California because of the 25 cent increase in the excise tax can be accounted for. Furthermore, this allows us to address the differences in taxes and prices among these neighbouring states, and to analyse evidence for other states near California, permitting greater confidence that the results obtained from California data are truly related to the tax change.

The results of the estimated demand model are discussed in the next section. This section will focus on the supply equation in which price is specified as the dependent variable. The price of cigarettes is a function of state taxes, input prices of cigarettes (for example, tobacco wholesale prices, wage, capital costs), the Herfindahl Index (for example, the measurement of the oligopoly structure of the cigarette industry), the future output of cigarettes, and a dummy variable controlling for the increase in the federal tax from 8 cents to 16 cents per pack in 1983. In an alternative model specification, state and year dummy variables replace the federal tax dummy variable.

According to the model (including state and year dummy variables), a one cent increase in the state tax is estimated to increase the retail price by 1.27 cents. Our results support the argument that the cigarette industry is not perfectly competitive because the burden of the tax increase has been passed on to consumers, so that prices have risen more than the increase in tax. Keeler et $a l^{4}$ analyse the effects of Proposition 99 on cigarette prices on based 
on panel analysis of state by state data for the years 1960 to 1990 . This study finds that a one cent increase in a state tax will raise the retail price by 1.27 cents. In essence, the results of the two studies are quite similar, despite the fact that the models are substantially different and the data are somewhat different between the two studies: those of Sung et $a l^{6}$ are based on panel data for the 11 Western states for 1967-90; those of Keeler et $a l^{4}$ are based on US data for 50 states during the 1960-1990 period. Sung et al based their analysis on a general model of oligopoly behaviour with rational addiction (explained in the next section), whereas Keeler et al based theirs on an oligopoly which coordinates prices around a monopoly nationwide wholesale price which wholesalers and retailers are free to arbitrage. So the two studies are done in the same spirit, but they differ somewhat in their assumptions and data.

\section{Demand effects and estimates of the price elasticity}

Using monthly cigarette sales data in California from January 1980 to December 1990, Keeler $e t a l^{8}$ applied an econometric model, based alternatively on assumptions of no addictive behaviour, rational addiction, and myopic addiction, to analyse the effects of price changes from Proposition 99 on cigarette consumption in California. Rational and myopic addiction refer to economic models of addictive behaviour, named and developed by Becker et $a l .{ }^{9}$ In practical terms, these economic models of addiction imply that consumption in periods other than the present affects present consumption. In the case of myopic addiction, because the consumer has built up a "habit" of consumption, past consumption (and the structural variables affecting it, such as past price) affect current consumption. In the case of rational addiction, both past consumption and future consumption affect current consumption (or, more plausibly stated, the past and future structural variables, including expected future prices, affect current consumption).

Variables included in the analysis are a monthly California cigarette price index, interstate tax difference variables, an anti-smoking regulation variable, and dummy variables representing seasonality and pre-tax hoarding period. The extent to which cigarette consumption declines in response to an increase in price can be measured with the price elasticity of demand for cigarettes. A price elasticity of -0.4 means that a $10 \%$ increase in price will lead to a $4 \%$ decrease in consumption. Under the assumption of myopic addiction, the price elasticity of demand for cigarettes in California is estimated to be -0.34 in the short run and -0.47 in the long run (at mean values for the data). The assumption of rational addiction generates a price elasticity estimate of -0.36 in the short run and -0.58 in the long run, again at mean values of the data. Finally, estimates based on the assumption of no economically addictive behaviour at all gen- erate an elasticity of -0.46 , very much like the long-run estimate with myopic addiction.

Sung et $a l^{6}$ also estimated the effect of California's increased cigarette tax on retail price in their demand model. The specified demand model closely follows the previous model for monthly California data. The estimated short run price elasticity is -0.40 and the long run price elasticity is -0.48 . These estimates are very similar to those obtained from Keeler $e t$ al. ${ }^{8}$

\section{Combined effects on supply and demand}

Sung et $a l^{6}$ found that the 25 cent increase in California's cigarette tax increased the retail price by $21.2 \%$ during the $1988-1990$ period. This increase in price reduced per capita cigarette consumption by $11.2 \%$ in the short run and $13.4 \%$ in the long run. These estimates are based on elasticity estimates measured at 1988 values. If the elasticity estimates are measured at sample values during $1980-1990$, as used in Keeler et al, ${ }^{8}$ the 25 cent tax increase would reduce consumption by $9.8 \%$ in the short run and by $11.7 \%$ in the long run.

For a comparison of the results, consider the illustrative calculation based on Keeler et al. ${ }^{8}$ Note first that between November 1988 and November 1989, the real price of a pack of cigarettes rose by $25 \%$ in California. Nearly all this is likely to be due to the increase in the state excise tax following Proposition 99. This means that the short run effect of proposition 99 was to reduce consumption by $8.75 \%$ $(25 \% \times 0.35)$, and the long run effect would be to reduce cigarette consumption by $13 \%$ $(25 \% \times 0.52)$. The average of the short run price elasticities estimated from the myopic and rational addiction models in Keeler $e t a l^{8}$ is 0.35 , whereas 0.52 is the average of the long run elasticities from the myopic and rational addiction models in that study.

The results from the two models just discussed and the time-series analysis (to be presented in the next section) are summarised in the table. It is important to note that the predicted effects of Proposition 99 are quite consistent across these studies, even though each study uses very different data, model specifications, and estimation methods. They all tell a similar story, namely that the cigarette price increase from higher taxes due to Proposition 99 reduced cigarette consumption in California by $8-9 \%$ in the short run and $10-13 \%$ in the long run.

\section{TIME-SERIES ANALYSIS OF PROPOSITION 99}

Hu et $a l^{10}$ assess the effect of Proposition 99 on cigarette sales by using a time-series model. The dependent variable is the monthly per capita sales of cigarettes, expressed as packs per civilian adult (defined as persons aged 15 and older) during the period of January 1984 to December 1991. The explanatory variables include an event variable, which is represented as a dichotomous variable, with a value of 1 for the months following January 1, 1989, when 
Summary of economic effects of Proposition 99

\begin{tabular}{|c|c|c|c|c|c|}
\hline \multirow[b]{3}{*}{ Study } & \multirow[b]{3}{*}{ Dataset } & \multirow{2}{*}{\multicolumn{2}{|c|}{ Estimated price elasticity ${ }^{a}$}} & \multicolumn{2}{|c|}{$\begin{array}{l}\text { Percent reduction } \\
\text { in consumption } \\
\text { from surtax }\end{array}$} \\
\hline & & & & & \\
\hline & & Short run & Long run & run & run \\
\hline Hu et $a l^{10}$ & $\begin{array}{l}\text { Monthly } \\
\text { California time- } \\
\text { series, 1984-91 }\end{array}$ & & & & 9.5 \\
\hline Keeler et $a l^{8}$ & $\begin{array}{l}\text { Monthly } \\
\text { California time- } \\
\text { series, 1980-90 }\end{array}$ & -0.3 to -0.4 & -0.5 to -0.6 & $8.8^{\mathrm{b}}$ & $13^{b}$ \\
\hline Sung et $a l^{6}$ & $\begin{array}{l}\text { Annual State } \\
\text { Panel (11 western } \\
\text { states), 1967-90, } \\
\text { Tobacco Institute }\end{array}$ & -0.4 & -0.48 & $9.8^{\mathrm{c}}$ & $11.7^{\mathrm{c}}$ \\
\hline
\end{tabular}

${ }^{\text {a }}$ Measured at sample means corresponding to each model.

Measured at sample means for 1980-90.

These figures are based on the price elasticity estimates measured at sample mean values for 1980-90, in order to be comparable to the calculation of price elasticity used in Keeler et al. ${ }^{8}$ The published results reported in Sung $e t \mathrm{al}^{6}{ }^{6}$ on the other hand, are based on the elasticity estimates measured at fiscal year 1988, during which Proposition 99 was passed.

Proposition 99 went into effect, and a value of 0 otherwise. The model also controls for time trend to take into account of the declining trend of the proportion of the population which smokes, a non-linear time variable to estimate the immediate and long term effects for the event, seasonal variables, and random monthly fluctuation. Since Proposition 99 was enacted two months before it took effect, these months are represented in the model by two additional dichotomous variables, one for each of these months. Finally, a dummy variable for the 1991 Federal tax increase (an additional 4 cents per pack) was also introduced.

The details of estimation method are reported elsewhere. ${ }^{11}$ The estimated results from $\mathrm{Hu}$ et $a l^{10}$ indicate a very large immediate effect from Proposition 99. One month after the implementation of Proposition 99, cigarette sales dropped by two packs per adult or a $25.7 \%$ decline. Part of this decline represents the offset from a high level of purchases in the preceding months, when smokers bought extra cigarette to avoid the tax increase. Sales in the prior month were one pack per adult $(10 \%)$ higher than expected. Over the longer term, the effect of Proposition 99 began to decay. By June 1989 (six months later), sales had declined only by 0.94 packs or $10.9 \%$. By the end of 1989 and throughout 1991, the decline of per capita sales had remained at a rate of 0.75 packs per adult per month or a $9.5 \%$ reduction.

One discrepancy which merits mention relates to the comparisons of the "short run" and "long run" between the time-series analysis and structure analysis. In the time-series analysis, the long run effect is smaller than its short run (immediate term) counterpart, whereas in the structural analysis, the opposite is true. The short run (immediate term) effects observed in time-series analysis are so transitory and may be an artefact of the measurement technique. We should note here that they are not likely to be so reliable as the long term ones. That is the reason why it has been excluded from the table, and why we do not emphasise it here. Otherwise, the measured effects are quite similar between the timeseries analysis and the aggregated structural models.

In addition to taxation, Proposition 99 employed an anti-smoking media campaign to reduce cigarette consumption. To separate out the effect of increased taxes from the effects of the anti-smoking campaign, $\mathrm{Hu}$ et $a l^{12}$ modify the above time-series model, including adding a variable to represent the expenditures on the statewide anti-smoking advertising campaign, and extending the data to 1992. Since advertising is thought to require repetition before the intended audience is reached, advertising expenditures were represented as a stock variable, that is, as the accumulation of past expenditures on the media campaign.

The results from $\mathrm{Hu}$ et $a l^{12}$ indicate that both the tax increase and the media campaign caused statistically significant reductions in California cigarette sales. Elasticities were calculated for the effect of taxation and the media campaign on cigarette sales during the post-Proposition 99 period (1989-1992). In this context, elasticity is a quantitative measurement which reflects the percentage change in cigarette sales resulting from either a $1 \%$ change in state taxes or a $1 \%$ change in anti-smoking media campaign expenditures. The elasticity of sales with respect to state tax was -0.30 , that is, a $10 \%$ increase in tax would result in a $3 \%$ reduction in sales. The elasticity of sales with respect to media expenditures was -0.05 , that is, a $10 \%$ increase in media expenditures would result in a $0.5 \%$ reduction in sales.

$\mathrm{Hu}$ et $a l^{12}$ also compared the magnitude of the effects of taxation and the anti-smoking media campaign on cigarette sales during the period between the third quarter of 1990 and the fourth quarter of 1992 . Sales dropped by 35 packs per adult over this 30 month period. This reduction included a decrease of 27.3 packs attributable to the effect of the tax increase, and 7.7 packs because of the media campaign. Thus $79 \%$ of the reduction was attributed to the increase in taxes and the remaining $21 \%$ reduction was attributable to anti-smoking advertisements.

\section{Policy implications, discussion, and conclusions}

So far, our concern has been with the effects of Proposition 99 on the retail price of cigarettes and on cigarette consumption in California. The effect on cigarette consumption is perhaps the most important issue that our study has analysed. There is, however, a related policy issue which is also worth considering: the use of the revenues generated by the tax. After considering that issue, we summarise our conclusions and discuss broader policy implications.

\section{ALLOCATION OF STATE TAX REVENUES}

Besides reducing cigarette consumption, imposing state cigarette tax also has an effect on state tax revenues, usually an increasing effect. If we argue that the cigarette tax is a " $\sin \operatorname{tax}$ " because smoking causes economic burden to the society, then we need to examine how the revenues collected from cigarette tax are allocated to relieve this burden. 
According to California Department of Health Services ${ }^{13}$ the excess hospital admissions cost for Californians amounted to $\$ 2.3$ billion in 1985. Public funds such as Medicare, Medical, and Medically Indigent paid for $77 \%$ of these hospital costs ( $\$ 1.8$ billion). Therefore, using tax revenues to fund these public health programmes directly defrays the excess medical cost of smoking. Alternatively, these revenues can be used to fund anti-smoking education programmes and a state sponsored anti-smoking media campaign as currently implemented in California. The media campaign may prevent potential smokers from initiating smoking and induce the current smokers to quit. Because of its impact on quitting among current smokers, the media campaign reduces the economic cost of smoking.

As specified by Proposition 99, 45\% of surtax revenues are allocated to indigent health care, $20 \%$ to health education and media campaign programmes, $5 \%$ are for parks, recreation, and environmental programmes, $5 \%$ are for research, and the remaining $25 \%$ are placed in an unallocated account. We do not have the data to analyse fully the relative cost-effectiveness of all potential expenditures from the tax revenues for improvement in public health (indeed, that is a research project in itself) - we can conclude here only that allocation of the revenues to an anti-smoking media campaign has been successful, in the sense of substantially and significantly reducing smoking, as explained above.

\section{SUMMARY AND CONCLUSIONS}

California's anti-smoking legislation, Proposition 99, is a major success for the voters of California. It has been followed by several other states in the country, such as New York, Massachusetts, Minnesota, and Michigan. Given the research questions posed at the beginning of the paper, plus the empirical analyses summarised here, we can conclude the following.

First, California retail cigarette prices rose substantially as a result of the tax increase-by our best estimates by as much $27 \%$ more than the amount of the tax.

Second, demand for cigarettes is rather strongly responsive to price, showing a price elasticity of -0.3 to -0.4 in the short run and -0.5 to -0.6 in the long run (for the purposes of this analysis, the short run can be thought of as under a year, whereas the long run can be thought of as a period of several years - in the neighbourhood of 3-4 years).

Third, combining supply and demand responses, Proposition 99 reduced cigarette consumption substantially in California, about $8-9 \%$ in the short run and $10-13 \%$ in the long run. These results for the long run are supported alike by studies following two different methods: time-series analysis and structural analysis.

An additional topic we have investigated relates to the effectiveness of the state's anti- smoking media campaign, also funded by Proposition 99. Our results, based on the timeseries analysis of $\mathrm{Hu}$ et al, ${ }^{12}$ indicate that the anti-smoking media campaign has indeed had a significant effect in reducing cigarette consumption: specifically, $21 \%$ of the reduction in cigarette consumption following Proposition 99 was due to the anti-smoking media campaign, and the remaining $79 \%$ was due to the tax increase. Thus, although the media campaign had less effect than the tax increase, nevertheless it did have a substantial and significant effect.

Both the increase in cigarette taxes and the anti-smoking media campaign appear to have advantages and disadvantages as public policies to deter smoking. The tax is an economical, highly effective, and revenue producing method of reducing cigarette consumption. Its disadvantages are that it can be regressive, to the extent that those who continue to smoke heavily after the tax increase may be to a significant degree in lower income groups; and, related to that, a tax increase may not deter from smoking some segments of the population that a media campaign might reach. Thus a media campaign may be a more costly (to the government) way of reducing smoking than a tax increase, but it may reach groups (people who are not price sensitive) which taxation cannot.

This research was supported by funds provided by the Cigarette and Tobacco Surtax Fund of the State of California through the Tobacco-Related Disease Research Program of the University of California, grant No RT12.

1 Lewit EM, Coate D. The potential for using excise taxes to reduce smoking. F Health Econ 1982; 1: 121-45.

2 Barzel Y. An alternative approach to the analysis of taxation. f Polit Econ 1976; 84: 1177-98.

3 Barnett PG, Keeler TE, Hu T. Oligopoly structure and the incidence of cigarette excise taxes. Department of Econincidence of cigarette excise taxes. Department of Economics, Universty of California at Berkeley, Working
Paper No 92-202, (September 1992). In press, $\mathcal{F}$ Public Paper.

4 Keeler TE, Hu T, Barnett PG, Manning WG, Sung H Tobacco taxation, demand, and oligopoly behavior : analysi and estimation with State Panel data. Working Paper Institute of Business and Economic Research, University of California, Berkeley (April 1994).

5 Harris JE. The 1983 Increase in the Federal Cigarette Excise Tax. In: Summers LH, ed. Tax policy and the economy 1. Cambridge MA: National Bureau of Economic Research and MIT Press, 1987: 87-111.

6 Sung H, Hu T, Keeler TE. Cigarette taxation and demand: an empirical model. Comtemp Econ Policy 1994; 7 : an empiric

7 The Tobacco Institute. The tax burden on tobacco: historical compilation, 1990. Washington: Tobacco Institute, 1991.

8 Keeler TE, Hu T, Barnett PG, Manning W. Taxation, regulation, and addiction: a demand function for cigarregulation, and addiction: a demand function for cigar12: $1-18$.

9 Becker GS, Grossman M, Murphy K. Rational addiction and the effect of price on consumption. Am Econ Rev $1991 ; 81: 237-41$.

$10 \mathrm{Hu}$ T, Bai J, Keeler T, Barnett PG, Sung H. The impact of 1989 California major anti-smoking legislation on cigarette consumption. $\mathcal{f}$ Public Health Policy 1994; 15 $26-36$.

$11 \mathrm{Hu}$ T, Bai J, Keeler T, Barnett PG. The impact of 1989 California major anti-smoking legislation on cigarette consumption: three years later. Economics Working Paper No 92-203. Berkeley: Institute of Business and Economic No 92-203. Berkeley: Institute of Business

$12 \mathrm{Hu}$ TW, Sung H, Keeler TE. Tobacco taxes and an antismoking media campaign: the California experience. $A m$ $f$ Public Health (in press)

13 California Department of Health Services. Health and economic impact of smoking: California, 1985. Technical Report No 2. Sacramento: California Chronic and Sentinel Diseases Surveillance Program (Novembe 1988). 